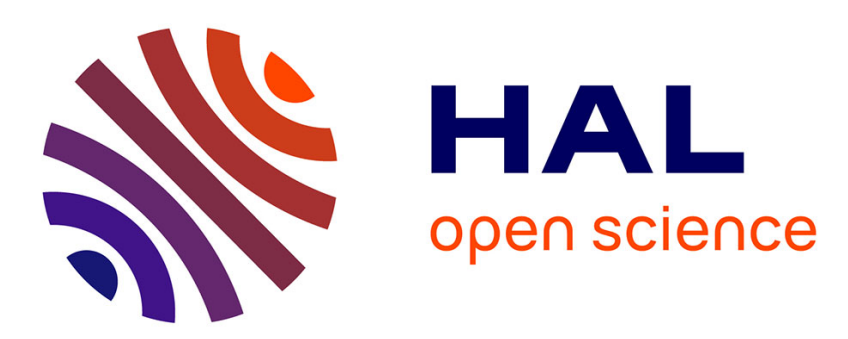

\title{
A three DOF linear ultrasonic motor for transport and micropositionning.
}

Soukalo Dembélé, Karima Rochdi

\section{To cite this version:}

Soukalo Dembélé, Karima Rochdi. A three DOF linear ultrasonic motor for transport and micropositionning.. Sensors and Actuators A: Physical , 2006, 125, pp.486-493. 10.1016/j.sna.2005.08.001 . hal-00263946

\section{HAL Id: hal-00263946 \\ https://hal.science/hal-00263946}

Submitted on 13 Mar 2008

HAL is a multi-disciplinary open access archive for the deposit and dissemination of scientific research documents, whether they are published or not. The documents may come from teaching and research institutions in France or abroad, or from public or private research centers.
L'archive ouverte pluridisciplinaire $\mathbf{H A L}$, est destinée au dépôt et à la diffusion de documents scientifiques de niveau recherche, publiés ou non, émanant des établissements d'enseignement et de recherche français ou étrangers, des laboratoires publics ou privés. 


\title{
A 3 DOF linear ultrasonic motor for transport and micropositioning
}

\author{
Sounkalo Dembélé, Karima Rochdi \\ Laboratoire d'Automatique de Besançon \\ ENSMM - UFC - UMR CNRS 6596 \\ 24, rue Alain Savary \\ 25000 Besançon, France
}

\begin{abstract}
The paper deals with the study and use of a linear ultrasonic motor at low voltages. Standing waves are generated in a $64 \times 38 \times 2.5 \mathrm{~mm}^{3}$ vibrator by 20 piezoelectric ceramics and converted into sliding motions by the friction between four legs and the worktop : translations and rotations are achieved. The speed of the motor is studied according to the amplitude and frequency of the driving voltage as well as the mass of the load. Then, a model of the system is retrieved for some set points and validated using a position control. According to its interesting performances for transport and positioning, the motor is used to motorize a moving palet for the transfer of parts in a microassembly workcell.
\end{abstract}

Keywords : linear ultrasonic motor, standing wave ultrasonic motor, piezoelectric ultrasonic motor, vision based localization, micropositioning, microassembly

\section{Introduction}

Like rotary ultrasonic motors (USM), two types of linear USM are considered according to the wave used to achieve the useful motion : standing wave type and travelling wave type. Uchino [1] notices that the first type is lower cost than the second type, because of the use of a single driving source instead of two for the second one (bi-mode). But, standing wave type USM are characterized by a problematic lack of control. In both cases, ultrasonic vibrations of a vibrator are translated into linear motion of a slider by the

\footnotetext{
*E-mail: sounkalo.dembele@ens2m.fr
} 
friction between the vibrator and the slider pressed against it. Those vibrations are usually performed by means of piezoelectric actuators.

Travelling wave USM are common in scientific literature. A longitudinal mode of the vibrator is combined with a bending one to achieve the travelling wave. With a vibrator of about $60 \mathrm{~mm}$ x $6 \mathrm{~mm}$ x $60 \mathrm{~mm}$ Hemsel et al. [2] achieved a speed of $220 \mathrm{~mm} / \mathrm{s}$ and a force of $25 \mathrm{~N}$. Snitka [3] achieved a speed of $150 \mathrm{~mm} / \mathrm{s}$, a force of $15 \mathrm{~N}$, a resolution up to $10 \mathrm{~nm}$ and a positioning accuracy of $0.3 \mu \mathrm{m}$. Friend et al.[4] built a motor whose vibrator is formed by four bimorphs ( $11.5 \mathrm{~mm} \times 4 \mathrm{~mm} \times 1.2 \mathrm{~mm})$, it achieved, a 181 $\mathrm{mm} / \mathrm{s}$ speed and a $150 \mathrm{~N}$ force. The motor of Roh et al.[5] was a saw-toothed vibrator of $75 \times 8 \times 6 \mathrm{~mm}^{3}$ which performed a speed of $400 \mathrm{~mm} / \mathrm{s}$ under 100 V. The USM of Bein et al.[6] was a vibrator-slider of $17.5 \times 1.5 \times 2.02 \mathrm{~mm}^{3}$ including two projections that performed a speed and force of $160 \mathrm{~mm} / \mathrm{s}$ and $0.25 \mathrm{~N}$ respectively. The USM of Zhai et al. [7] was a first longitudinal mode-fourth bending mode type like that of Bein et al. Its dimensions were $80 \times 10.1 \times 7.7 \mathrm{~mm}^{3}$. It achieved a speed of $300 \mathrm{~mm} / \mathrm{s}$ under $10 \mathrm{~V}$ and a loading capacity of $95 \mathrm{~g}$. The motor of Park et al.[8] was also like that of Bein et al., with the dimensions of $65 \mathrm{~mm} \times 5 \mathrm{~mm}$ x $18.3 \mathrm{~mm}$ it achieved a $600 \mathrm{~mm} / \mathrm{s}$ speed and a $0.1 \mathrm{~N}$ force.

In contrast with travelling wave USM only a few standing wave USM have been developed. Using a saw-toothed vibrator of $40 \mathrm{~mm} \times 10 \mathrm{~mm} \times 2 \mathrm{~mm}$ the USM from He et al.[9] performed a $200 \mathrm{~mm} / \mathrm{s}$ speed, a $0.15 \mathrm{~N}$ force and a $0.1 \mu \mathrm{m}$ resolution. That of Le Moal et al.[10] consisted of a $64 \mathrm{~mm} \times 38 \mathrm{~mm}$ x $2.5 \mathrm{~mm}$ vibrator-slider in bronze-beryllium, PZT ceramics and three $3 \mathrm{~mm}$ long cylindrical steel legs. The excitation of the sixth longitudinal vibration mode in the vibrator led to the longitudinal sliding of the system by the friction of the legs with the worktop which must be hard enough (glass or steel for example). The motor performances were a $180 \mathrm{~mm} / \mathrm{s}$ speed, a $2 \mathrm{~N}$ pushing force, a $1 \mu \mathrm{m}$ resolution, a $10 \mathrm{~kg}$ loading capacity and an unlimited travel range.

All the motors presented above have only one degree of freedom (DOF) and the majority of them has a limited travel range. The performances of the motor studied in the paper are similar to that of the literature (speed, force, resolution), but it has three DOF, an unlimited travel range and a high loading capacity. It is a 3 DOF version of the USM of Le Moal. In the following the principle of the motor is presented, its behaviour is studied at low driving voltages and its use for the transport of parts in a microassembly workcell is discussed.

\section{Principle of the motor}

As explained above, the USM studied is a vibrator-slider capable of translation and rotation on hard worktops. A set of $4 \times 5$ PZT ceramics polarized 
bottom-up is glued on a $64 \mathrm{~mm} \times 38 \mathrm{~mm} \times 2.5 \mathrm{~mm}$ bronze-beryllium plate in order to excite standing waves in the latter. Four steel legs, $3 \mathrm{~mm}$ long, are judiciously bonded at the bottom of the vibrator (figure 1), their friction with the worktop converts the standing waves into sliding motions. The weight of the system is $70 \mathrm{~g}$. In the experiments reported here a glass worktop is used, but any hard flat surface is suitable.

Le Moal et al.[10] studied this kind of motor (in a version with three legs and then only one DOF). It can be modeled as a mass (the vibrator and the load carried) connected with a spring (the legs supposed elastic) and actuated by the piezoelectric force from the PZT ceramics. Since every leg is positioned outside nodes and antinodes of the standing vibrations, it jumps, sticks and slips on the worktop (figure 2). This principle is valid for any rectangular vibrator : longitudinal (respectively transversal) vibration produces longitudinal (respectively transversal) sliding if the legs are correctly indexed according to the vibration. Because of the mechanical properties of the bronze-beryllium alloy (mass density of $8250 \mathrm{~kg} . \mathrm{m}^{3}$, Young modulus of $1.2310^{11}$ N.m ${ }^{-2}$, Poisson ratio of 0.31) Le Moal et al. used a finite element modelling to calculate the geometric parameters (length, width, thickness) and the frequencies of the vibrating modes. They showed that for a given leg indexation a lot of modes could produce sliding, but only ultrasonic modes with inaudible frequencies and lower than $100 \mathrm{kHz}$ are used. Their motor is characterized by a low energy consumption (about $100 \mathrm{~mA}$ ), low pushing force (less than $2 \mathrm{~N}$ ) that makes straight trajectories impossible without the closed loop of the pose, an unlimited travel range, a high resolution (about $1 \mu \mathrm{m}$ ) and a high loading capacity (up to $10 \mathrm{~kg}$ ).

In our case, the motor has four legs positioned on the vibrator as indicated in figure 1. The organisation of the ceramics allows the excitation of the fourth and sixth longitudinal (along $X$ axis) vibration modes of the vibrator, and the third and fifth transversal(along $Y$ axis) vibration modes. For the characterization of every mode, a ceramic is bonded at the bottom of the vibrator and the voltage delivered is measured.

By applying the voltage $U \sin 2 \pi f t$ to the ceramics $1,2,3,4,17,18,19,20$ (figure 1) and the voltage $U \sin (2 \pi f t+\pi)$ to the other ceramics, the sixth longitudinal mode is sustained in the vibrator by the successive tractions and compressions of the ceramics. The ratio in decibels of the amplitude of the voltage from the bottom ceramic to the amplitude of the driving voltage (Bode diagram) is recorded versus the frequency : the resonance frequency is $35.7 \mathrm{kHz}$ (figure 3). The achievement of this vibration leads to the sliding of the system along $X$ axis in the increasing direction $\left(X^{+}\right.$motion) by the friction of the legs with the worktop.

If the voltage $U \sin 2 \pi f t$ is applied to the ceramics $2,4,6,8,9,11,14,16$, 18, 20 (figure 1) and the voltage $U \sin (2 \pi f t+\pi)$ to the other ceramics, the fifth transversal mode is excited : the resonance frequency is measured to $63 \mathrm{kHz}$. This vibration produces the sliding of the system along the $Y$ axis 


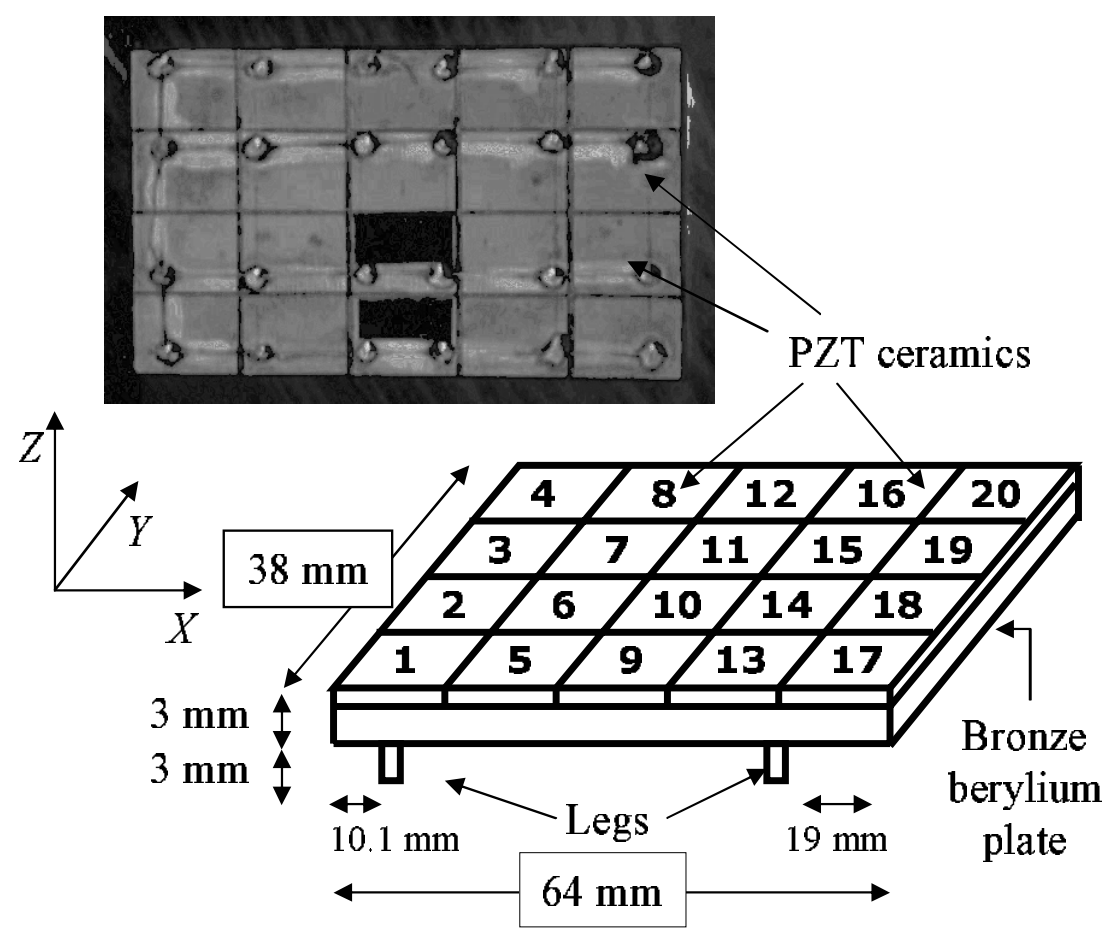

Figure 1: Schematic view of the USM 


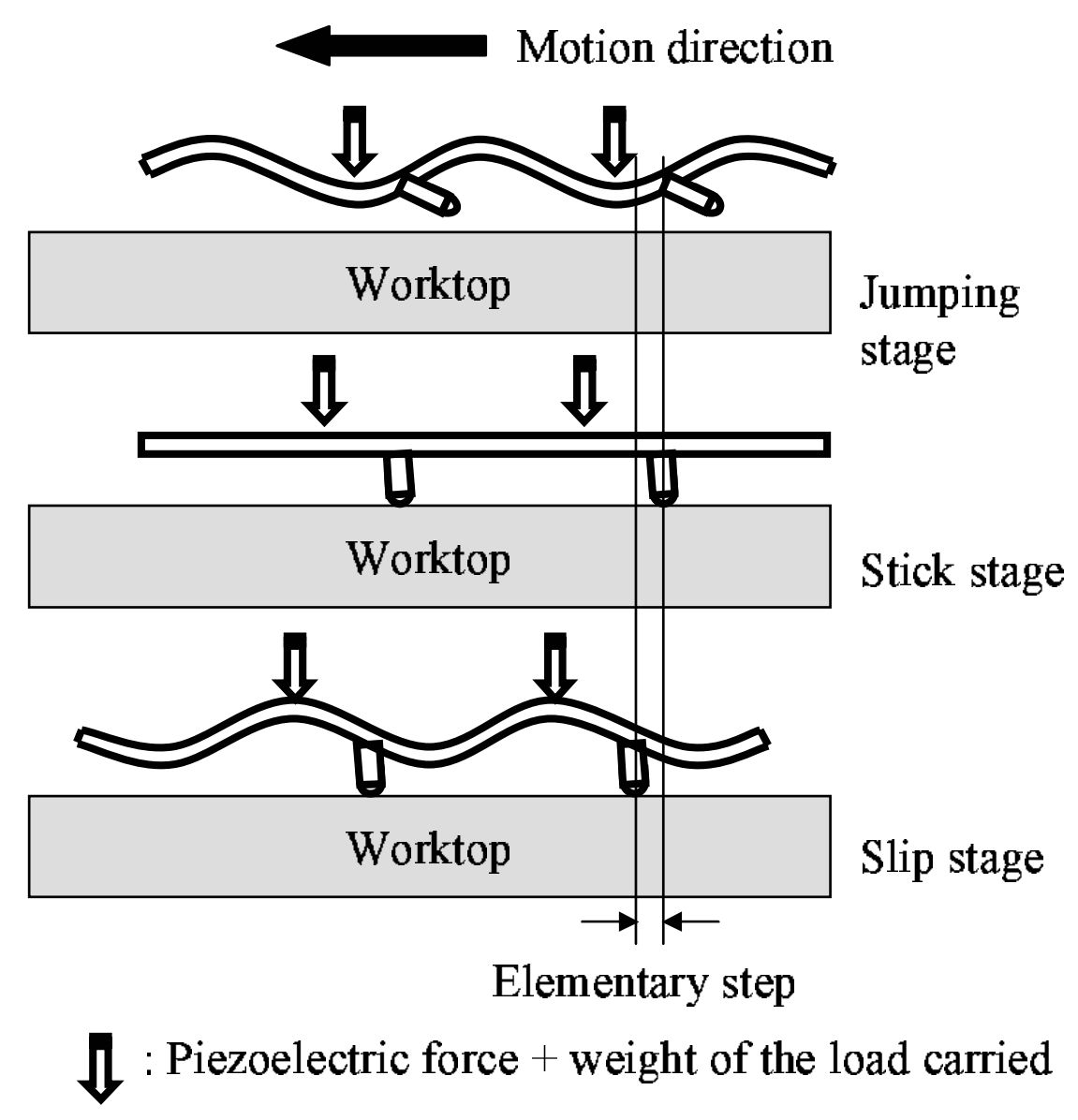

Figure 2: Principle of the USM motion 


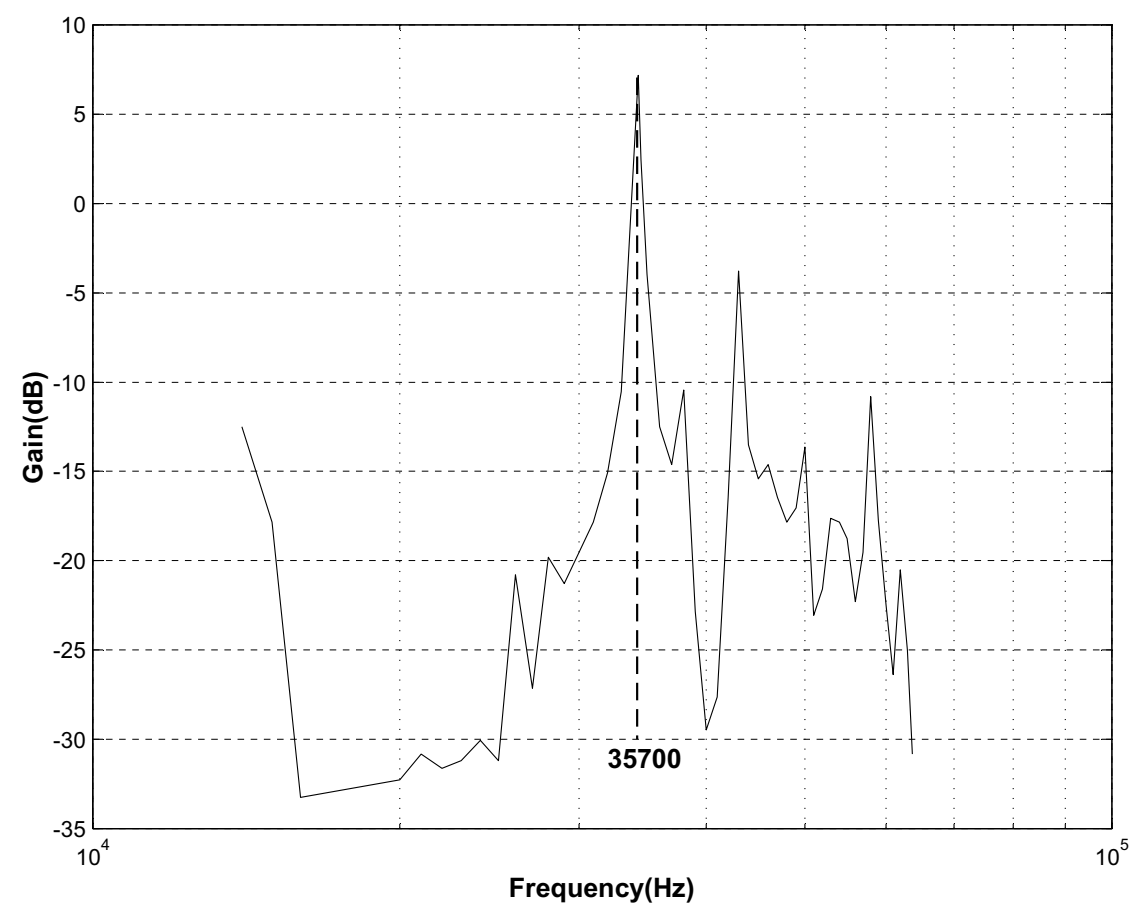

Figure 3: Bode diagram of the longitudinal bending mode producing $X^{+}$ displacement

in the increasing direction $\left(Y^{+}\right.$motion).

The motions $X^{-}$and $Y^{-}$are achieved respectively by the longitudinal fourth mode (resonance frequency of $15.4 \mathrm{kHz}$ ) and the transversal third mode (resonance frequency of $20 \mathrm{kHz}$ ).

The rotations around $Z$ are obtained by exciting degenerated modes, i.e. out of the resonance, the fifth transversal mode is used : $26.5 \mathrm{kHz}$ for $\Theta^{+}$ and $19.5 \mathrm{kHz}$ for $\Theta^{-}$.

The motions and the corresponding frequencies are listed in table 1 . These results were found empirically.

The paper focuses on the speed of the four legs and 3 DOF motor, particularly the $X$ and $Y$ motions. For that purpose a contactless localization method was developped using a vision system.

A simple black pattern of $7 \mathrm{~mm} \times 3 \mathrm{~mm}$ is bonded at the top of the motor and observed through a standard monochrome CCD camera with a zoom and connected to a 8-bits acquisition card. The grey level images of the pattern are recorded, calibrated, corrected and processed using Matrox Imaging Library in order to locate the motor, i.e. to determine the position of the centre of gravity of the blob corresponding to the pattern as well as its orientation. The grey level image is thresholded in order to get a binary image 


\begin{tabular}{|l|c|}
\hline Motion & Frequency $(\mathrm{kHz})$ \\
\hline \hline$X^{+}$ & 35.7 \\
\hline$X^{-}$ & 15.4 \\
\hline$Y^{+}$ & 63 \\
\hline$Y^{-}$ & 20 \\
\hline$\Theta^{+}$ & 26.5 \\
\hline$\Theta^{-}$ & 19.5 \\
\hline
\end{tabular}

Table 1: Functional characteristics of the USM

(black and white image), the target blob is selected and its centre of gravity, $\mathrm{G}$, is computed ([11]).

The accuracy of the method according to the limitations of the vision system (light variations, noise from the camera, errors from the 8 bits acquisition card, image processing limits) is about 0.05 pixel i.e. $2.5 \mu \mathrm{m}$ since the pixel size is $50 \mu \mathrm{m}$, for a workfield of about $4 \times 3 \mathrm{~cm}^{2}$. The high advantage of the contactless localization system is to avoid any disturbance of the motor behaviour and then the latter can be studied accurately.

\section{Static behaviour}

The motor behaviour depends on the frequency and the amplitude of the driving voltage and on the mass of the load carried. Experiments were performed in order to investigate the effects of these parameters on the motor speed.

Firstly, the speed was recorded versus the driving frequency for an amplitude of $15 \mathrm{Vpp}$ and four values of the load mass $(0 \mathrm{~g}, 200 \mathrm{~g}, 400 \mathrm{~g}, 650 \mathrm{~g})$. The results are depicted in figure 4 . For every motion, the speed is maximal if the driving frequency is close to the resonance frequency of the vibrator. However, the motion is observed over a frequency excursion of about \pm 500 $\mathrm{Hz}$ around the resonance frequency. If the driving frequency moves away from the resonance frequency, the motor speed decreases toward zero. The maximal speed (about $20 \mathrm{~mm} / \mathrm{s}$ ) is achieved for $X^{+}$and $Y^{+}$motions since the motor is designed in priority for these motions. It also appears that for all the motions the best results are obtained for a $400 \mathrm{~g}$ load.

Secondly, the speed was recorded versus the driving amplitude at the resonance frequencies for $400 \mathrm{~g}$ load (figure 5). A dead zone is observed : no motion is achieved while the driving amplitude is less than $4 \mathrm{Vpp}$, above that value the speed grows up in a nonlinear way.

According to the previous results, some set points were defined : $400 \mathrm{~g}$ load, resonance frequency, amplitude of $15 \mathrm{Vpp}$ and $5 \mathrm{Vpp}$. At these points, the dynamic behaviour of the motor was studied and modeled. 

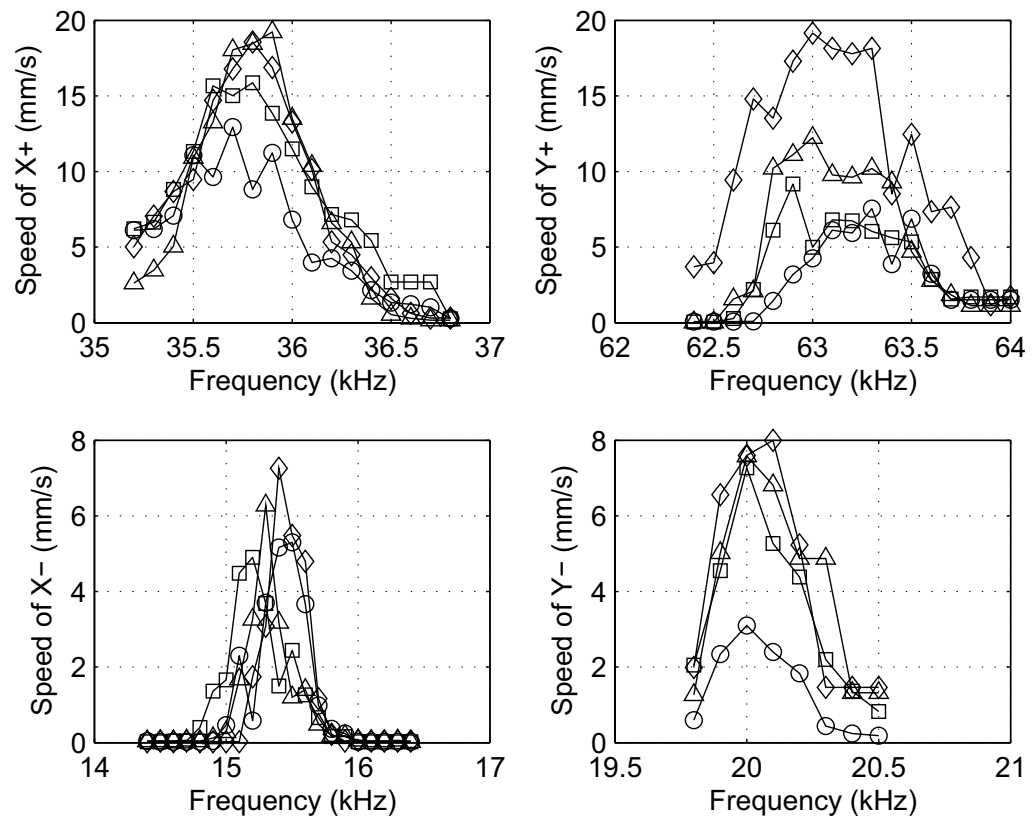

Figure 4: Speed versus driving frequency for the elementary motions for four values of the load mass (circle : $0 \mathrm{~g}$, square : $200 \mathrm{~g}$, diamond : $400 \mathrm{~g}$, triangle : $650 \mathrm{~g})$ 


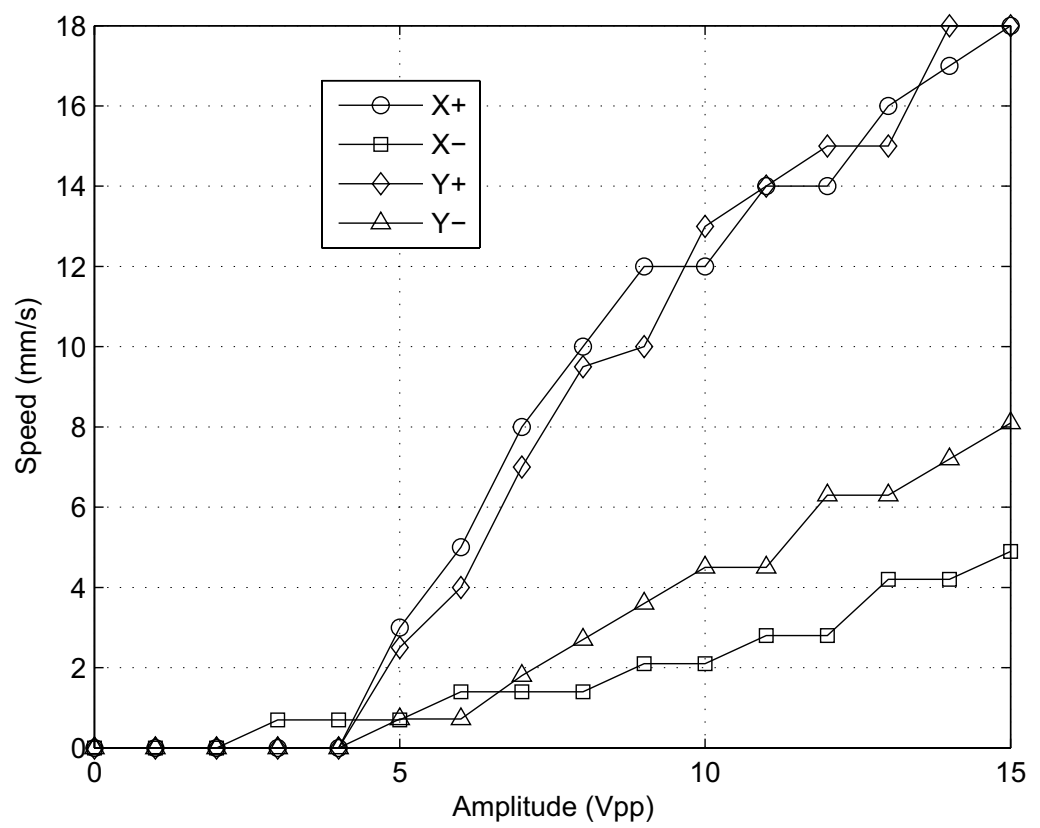

Figure 5: Speed versus driving amplitude for the elementary motions

\section{Dynamic behaviour}

The speed response of the motor was recorded at the set points defined above (figure 6). Every response consists of a transient state where the speed increases quickly from zero to a defined value, and a steady state where the speed stays around this value. That leads us to try to represent the motor behaviour by a first order model whose input and output are respectively the speed $v(t)$ and the driving voltage $u(t)$ :

$$
\tau \frac{d v(t)}{d t}+v(t)=k u(t)
$$

$k$ is the gain constant and $\tau$ the time constant of the model, $t$ is the variable time.

The application of Laplace transformation to this equation leads to the following transfert function :

$$
H(s)=\frac{V(s)}{U(s)}=\frac{k}{1+\tau s}
$$

where $V(s)$ and $U(s)$ are respectively the Laplace transform of $v(t)$ and $u(t)$. As each set point is defined by a constant driving voltage $u_{0}$ the solution of 

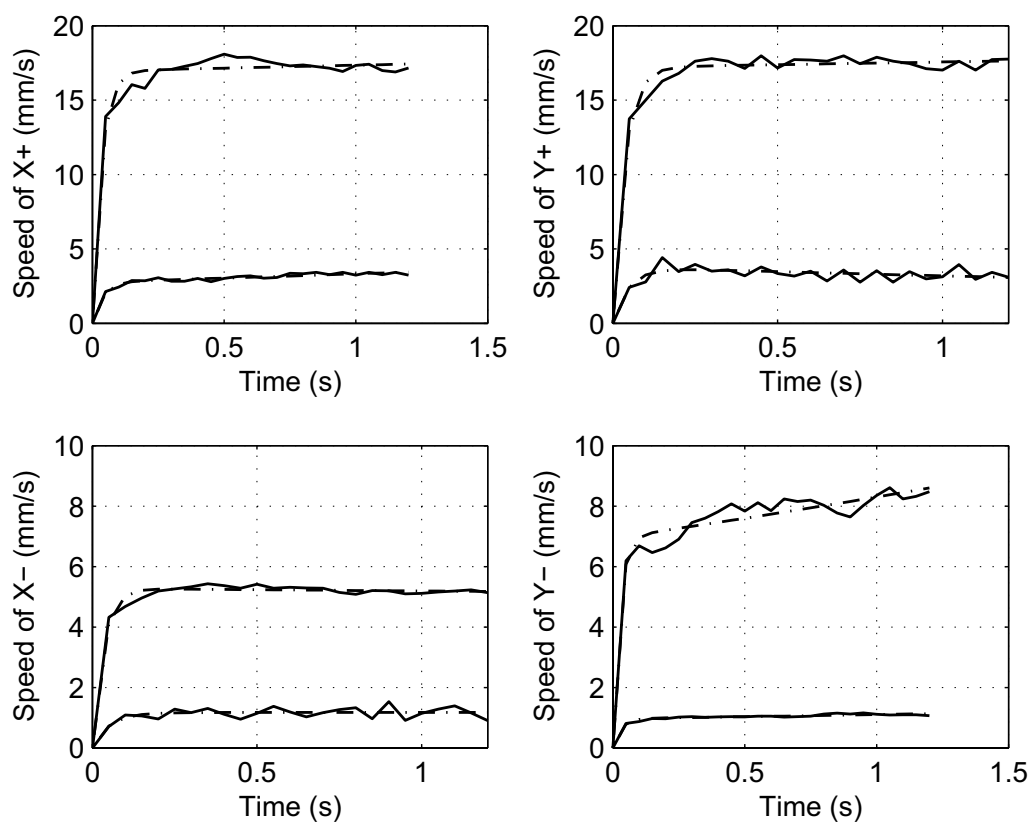

Figure 6: Speed response with 400g load at resonance frequencies (- : experimental, -. : identified, high speed : $15 \mathrm{Vpp}$, low speed : 5Vpp)

the equation is :

$$
v(t)=k u_{0}-k u_{0} e^{\frac{-t}{\tau}}
$$

We use a simplex method implemented in Matlab to fit the experimental curves by the following function :

$$
f(t)=c_{1} e^{-\lambda_{1} t}+c_{2} e^{-\lambda_{2} t}
$$

$c_{i}$ and $\lambda_{i}$ are the parameters to search for. Theirs values are summarized in table 2 . They indicate that the motions $X^{+}$at $15 \mathrm{Vpp}, X^{-}$at $15 \mathrm{Vpp}, X^{-}$ at $5 \mathrm{Vpp}, Y^{+}$at $15 \mathrm{Vpp}$ can be represented by first order systems since the coefficient $\lambda_{1}$ is neglectible. Then, it is possible to calculate the parameters

$$
\begin{gathered}
\tau=\frac{1}{\lambda_{2}} \\
k=\frac{c_{1}-c_{2}}{2 u_{0}}
\end{gathered}
$$

The values of the parameters are summarized in table 3 . 


\begin{tabular}{|c|c|c|c|c|c|}
\hline Motion & $u_{0}(\mathrm{Vpp})$ & $\lambda_{1}$ & $\lambda_{2}$ & $c_{1}$ & $c_{2}$ \\
\hline \hline$X^{+}$ & 15 & -0.0228 & 29.6012 & 16.9523 & -16.8579 \\
\cline { 2 - 6 } & 5 & -0.1808 & 26.0551 & 2.7752 & -2.7645 \\
\hline$X^{-}$ & 15 & 0.0165 & 30.6400 & 5.2780 & -5.2566 \\
\cline { 2 - 6 } & 5 & -0.0017 & 19.3685 & 1.1711 & -1.1711 \\
\hline$Y^{+}$ & 15 & -0.0205 & 28.0368 & 17.2023 & -17.1054 \\
\cline { 2 - 6 } & 5 & 0.1683 & 21.0890 & 3.7744 & -3.7933 \\
\hline$Y^{-}$ & 15 & -0.1769 & 40.0201 & 6.9530 & -6.9443 \\
\cline { 2 - 6 } & 5 & -0.1288 & 32.3401 & 0.9695 & -0.9666 \\
\hline
\end{tabular}

Table 2: The coefficients obtained from the fitting algorithm

\begin{tabular}{|c|c|c|c|}
\hline Motion & $u_{0}(\mathrm{Vpp})$ & $\tau(\mathrm{ms})$ & $k(\mathrm{~mm} / \mathrm{s} / \mathrm{Vpp})$ \\
\hline \hline$X^{+}$ & 15 & 33.8 & 1.1270 \\
\hline$X^{-}$ & 15 & 32.6 & 0.3512 \\
\cline { 2 - 4 } & 5 & 51.6 & 0.2342 \\
\hline$Y^{+}$ & 15 & 35.7 & 1.1436 \\
\hline
\end{tabular}

Table 3: The effective motor model parameters

But, the others motions cannot be represented by first order systems. However they can be approximated by this kind of model, if we neglect the coefficient $\lambda_{1}$, which is low. Considering this assumption, the above formulas are used to compute the model parameters. The approximated parameters are summarized in table 4 .

The USM motions are not homogeneous, the main explanation seems to be the fact that the fabrication process is not optimized : the ceramics and the leg are just glued on the surface of the vibrator, so the vibrations are not homogeneous and a problem of isostatism exists .

Let us note $G_{X^{+}}^{15}(s), G_{X^{+}}^{5}(s), G_{X^{-}}^{15}(s), G_{X^{-}}^{5}(s), G_{Y^{+}}^{15}(s), G_{Y^{+}}^{5}(s), G_{Y^{-}}^{15}(s)$, $G_{Y^{-}}^{5}(s)$ the respective corresponding transfert function.

In order to verify the validity of these models a control of the motor position is implemented and experimental results are compared with simulated ones. The stages of the algorithm are :

1- the motor is driven in order to perform a predefined step,

\begin{tabular}{|c|c|c|c|}
\hline Motion & $u_{0}(\mathrm{Vpp})$ & $\tau(\mathrm{ms})$ & $k(\mathrm{~mm} / \mathrm{s} / \mathrm{Vpp})$ \\
\hline \hline$X^{+}$ & 5 & 38.4 & 0.5540 \\
\hline$Y^{+}$ & 5 & 47.4 & 0.7568 \\
\hline$Y^{-}$ & 15 & 25 & 0.4632 \\
\cline { 2 - 4 } & 5 & 30.9 & 0.1936 \\
\hline
\end{tabular}

Table 4: The approximated motor model parameters 


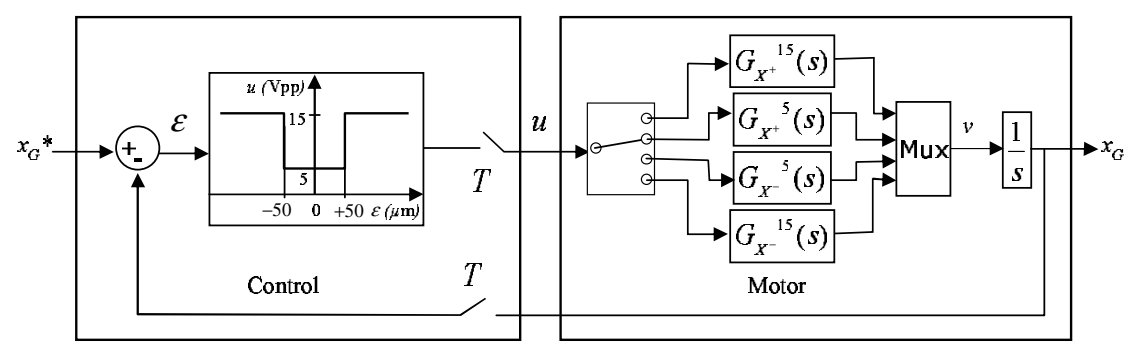

Figure 7: Block diagram modeling the behaviour of the USM

2 - the position is computed using the vision system,

3 - the position is compared with the set position, if the latter is reached the control is stopped else the process continues at stage 1 .

Coarse and fine steps are combined : a step of about $5 \mu \mathrm{m}$ is performed if the motor is less than $50 \mu \mathrm{m}$ from the set position (fine positioning), a step of about $20 \mu \mathrm{m}$ is performed otherwise (coarse positioning). The coarse and fine steps are obtained respectively for a driving voltage of $15 \mathrm{Vpp}$ and 5 Vpp. The control algorithm is implemented in $\mathrm{C}++$ with the real USM and in Matlab/Simulink with the model of the USM. Figure 7 shows the corresponding block diagram for $X$ motion : the driving voltage $u$ is switched to one of the transfert function $G_{X^{+}}^{15}(s), G_{X^{+}}^{5}(s), G_{X^{-}}^{15}(s), G_{X^{-}}^{5}(s)$ according to the value of error signal $\epsilon$, the speed $v$ is taken at the output of a multiplexer (MUX) and integrated to obtain the position $x_{G} . x *_{G}$ is the set position, $T$ is the sampling time since the control is digital even though the system model is analog.

At $15 \mathrm{Vpp}$, simulation results quite match experimental ones, but at $5 \mathrm{Vpp}$, the results do not match at all. $5 \mathrm{Vpp}$ is quite too low for the driving of the USM : the legs just begin to slip and their motions are not predictible. Finally, for very low driving voltages, the USM cannot be represented by a first order system.

\section{Application}

The interesting characteristics of the motor at low voltages $(2.5 \mu \mathrm{m}$ accuracy, $500 \mathrm{~g}$ load carrying capacity, unlimited travel range) led us to use it for the motorization of a palet meant to the transfer and positioning of microparts inside a microassembly workcell. The latter is made up of a 50 $\mathrm{cm} \times 50 \mathrm{~cm}$ glass worktop equipped with rails in order to guide the mobile palet and IR sensors to detect the occurrence of the palet at specific points (assembly station, corners). The parts are handled by an industrial manipulator (Adept Cobra) endowed with a microgripper. The latter was initially developped by Haddab et al.[12]. It is made up of two piezoelectric 

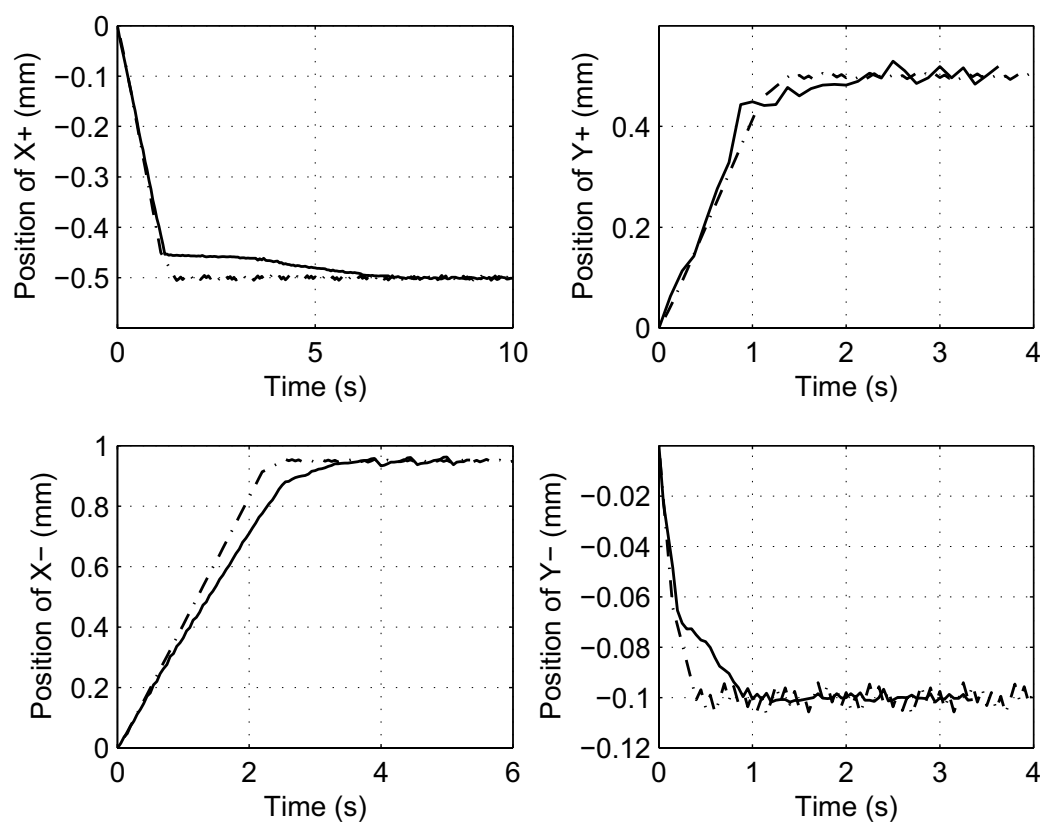

Figure 8: Position response of the USM (- : Experimental result, -. : Simulation result)

unimorphs separated by an adjustable beam which determines the size of the parts to manipulate. In future work, a micromanipulator will be used instead of the Adept manipulator. The control of the whole cell is made through the manipulator controller. Figure 9 shows a photography of the microassembly cell.

The task of inserting a piece of paper in a $500 \mu \mathrm{m}$ cleft was performed. The success rate was about $30 \%$. The main problem was the $9 \mu \mathrm{m}$ positioning repeatability of the palet at the assembly station. As the driving voltage is low the sliding force is very low, then the motor motion is random and perturbed by the driving cables and the rails. To overcome this problem an autonomous palet is under development : it carries two batteries for energy supply and a HF communication system for the control (figure 10).

\section{Conclusion}

Experimental investigations at low voltages on a three DOF linear USM are reported. Standing waves sustained in a vibrator are converted into rigid body motions by the friction of four legs with a glass worktop. The speed depends on the frequency and amplitude of the driving voltage and on the mass of the load carried. The frequency of the driving voltage must be kept 


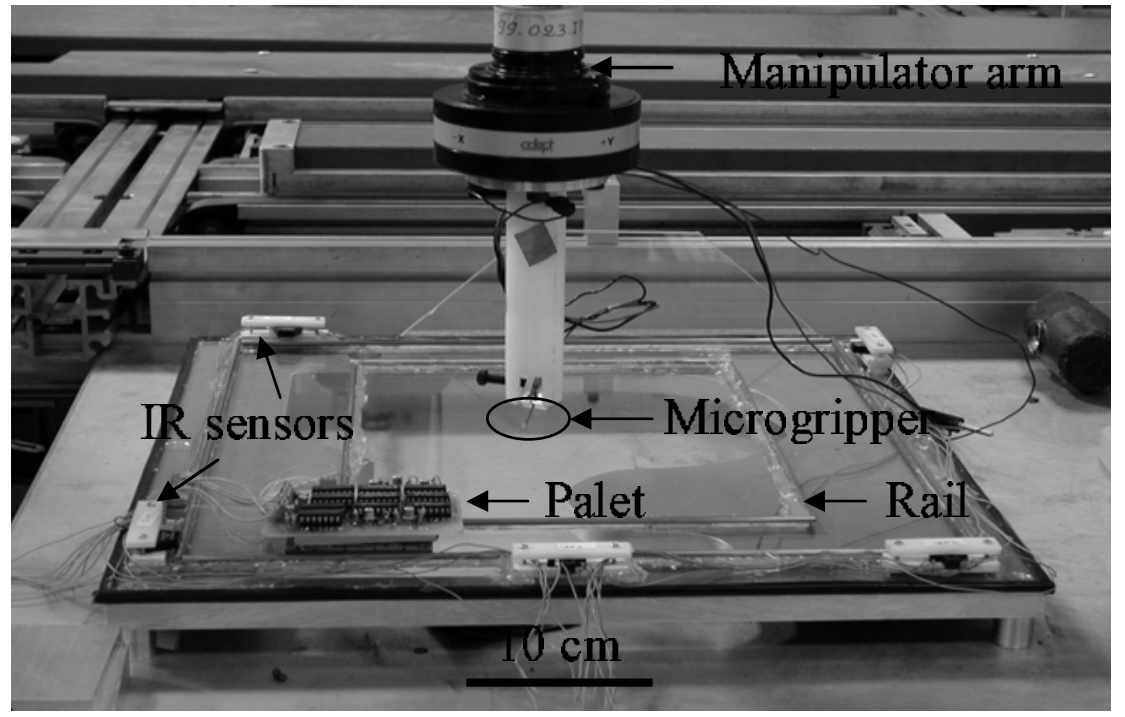

Figure 9: A view of the microassembly workcell

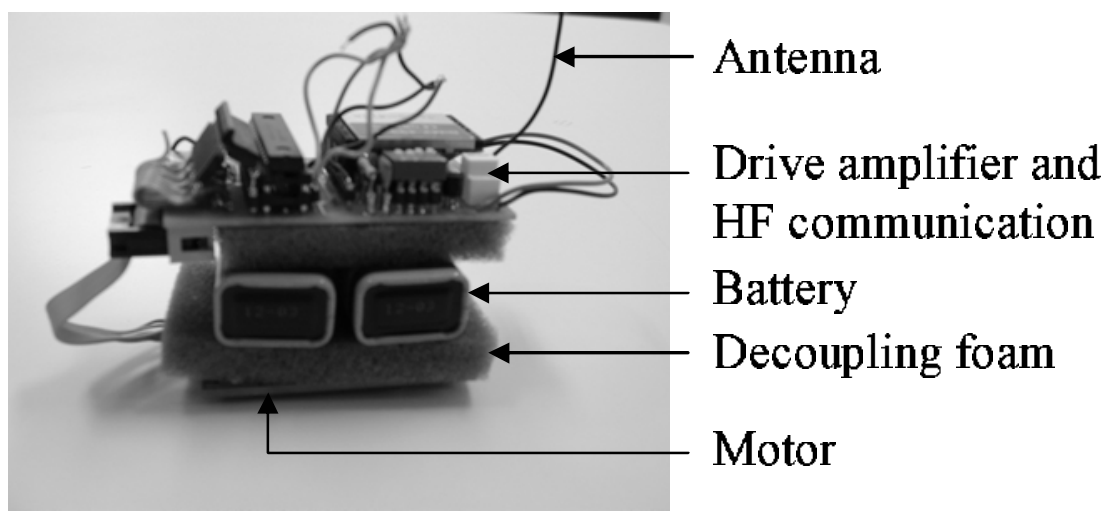

Figure 10: The first version of the autonomous mobile palet 
within a $\pm 500 \mathrm{~Hz}$ distance from the resonance frequency of the vibrator. The amplitude of the driving voltage must be superior to $4 \mathrm{Vpp}$, the mass of the load must be superior to $200 \mathrm{~g}$. These results allowed the definition of set points where the speed response was characterized. Then first order models were deducted and their validaty were studied using a position control of the motor. At the end, the motor was used to motorize a mobile palet for the transfer and micropositioning of parts inside a microassembly workcell because of its interesting performances at low driving voltages : 2.5 $\mu \mathrm{m}$ accuracy, $500 \mathrm{~g}$ load carrying capacity, $3 \mathrm{DOF}$, unlimited travel range. The paper shows that a 3 DOF linear USM can be built by using a little rectangular plate. The latter must be a right resonator and optimized to achieve longitudinal and transversal vibration modes. The position of the legs must be adjusted to these modes. This kind of motor presents interesting characteristics for transport and positioning of load : micrometer position resolution, hundreds of g of loading capacity, unlimited travel, low voltage driving capacity. An other characteristic is its ability to downsizing : the decreasing of the dimensions of the plate just implies the modification of the vibration modes. To improve its performances it is necessary to change the fabrication process. The use of microtechnology is a solution.

\section{References}

[1] K. Uchino. Piezoelectric ultrasonic motors : overview. Smart Mater. Struct., 7:273-285, 1998.

[2] T. Hemsel and J. Wallaschek. Survey of the present state of the art of piezoelectric linear motors. Ultrasonics, 38:37-40, 2000.

[3] V. Snitka. Ultrasonic actuators for nanometre positioning. Ultrasonics, $38: 20-25,2000$.

[4] J. Friend, A. Umeshima, T. Ishii, K. Nakamura, and S. Ueha. A piezoelectric linear actuator formed from a multitude of bimorphs. Sensors and Actuators A, 109:242-251, 2004.

[5] Y. Roh, S. Lee, and W. Han. Design and fabrication of a new traveling wave-type ultrasonic linear motor. Sensors and Actuators A, 94:205$210,2001$.

[6] T. Bein, E. J. Breibach, and K. Uchino. A linear ultrasonic motor using the first longitudinal and the fourth bending mode. Smart Mater. Struct., 6:619-627, 1997.

[7] B. Zhai, S-P. Lim, K-H. Lee, S. Dong, and P. Lu. A modified ultrasonic linear motor. Sensors and Actuators, 86:154-158, 2000. 
[8] T. Park, B. Kim, M-H. Kim, and K. Uchino. Characteristics of the first longitudinal-fourth bending mode linear ultrasonic motors. Jpn J. Appl. Phys., 41:7139-7143, 2002.

[9] S. He, W. Chen, X. Tao, and Z. Chen. Standing wave bi-directional linearly moving ultrasonic motor. IEEE Transactions on Ultrasonics, Ferroelectrics and Frequency Control, 45(5):1133-1139, 1998.

[10] P. Le Moal, E. Joseph, and J. C. Ferniot. Mechanical energy transductions in standing wave ultrasonic motors :analytical modelling and experimental investigations. Eur. J. Mech. A/Solids, 19:849-871, 2000.

[11] Matrox Imaging. Matrox imaging library, version 7.0 : User guide. Matrox Electronic Systems Ltd, Canada, 2001.

[12] Y. Haddab, N. Chaillet, and A. Bourjault. A microgripper using smart piezoelectric actuators. IROS'2000, Takamatsu, Japan, 2000. 